\title{
Analisis Perancangan Jembatan Rangka Batang Canai Dingin Pejalan Kaki Tipe Lower Deck berdasarkan Eurocode 3 dan SNI 7971:2013
}

\author{
ERMA DESMALIANA, AMATULHAY PRIBADI, YOPI FAISAL NURRACHMAN
}

\author{
Jurusan Teknik Sipil, Institut Teknologi Nasional Bandung \\ Email: ermadesmaliana@itenas.ac.id
}

\begin{abstract}
ABSTRAK
Jembatan rangka batang canai dingin pejalan kaki merupakan jembatan yang terdiri dari batang-batang profil yang terhubung berbentuk segitiga dan dominan menerima gaya tarik atau tekan, serta ditujukan khusus untuk pejalan kaki dan kendaraan ringan. Penelitian ini bertujuan untuk mengkaji tentang perancangan jembatan pejalan kaki tipe dek bawah menggunakan material canai dingin berdasarkan Standar Nasional Indonesia (SNI) 7971:2013 dan Eurocode 3 dengan menggunakan program SAP2000. Hasil perancangan awal didapatkan profil 2 295x64x2 untuk gelagar memanjang dan melintang, batang vertikal dan horisontal, serta profil 2C95x70x2 untuk batang diagonal. Hasil analisis program SAP2000 menunjukkan bahwa jembatan rangka batang tipe dek bawah memiliki nilai lendutan sebesar 1,1 mm. Berdasarkan hasil analisis didapatkan bahwa rasio beban terhadap kapasitas penampang batang tarik dan batang tekan jembatan rangka batang tipe dek bawah bernilai 0,426 dan 0,445 untuk Eurocode 3, sedangkan untuk SNI 7971:2013 bernilai 0,602 dan 0,545.
\end{abstract}

Kata Kunci: jembatan rangka batang, canai dingin, pejalan kaki, dek bawah, SNI 7971:2013, Eurocode 3

\begin{abstract}
Pedestrian cold formed truss bridge consists of connected profile members in a triangular shape and predominantly transfer tensile or compressive forces, and specifically intended for pedestrians and light vehicles. This research intends to examine the design of lower deck pedestrian cold formed bridge based on the Indonesian National Standard (SNI) 7971: 2013 and Eurocode 3 using the SAP2000 program. Preliminary design results obtained 2C95x64x2 profiles for longitudinal and transversal girders, vertical and horizontal members, and 2C95x $70 \times 2$ profiles for diagonal members. The result of SAP2000 program analysis shows that the deflection of lower deck truss bridge is $1.1 \mathrm{~mm}$. Based on the results of the analysis, it obtained that the ratio of the load to the tension and compression crosssectional capacity of the lower deck truss bridge is 0.426 and 0.445 for Eurocode 3, while for SNI 7971:2013 is 0.602 and 0.545.
\end{abstract}

Keywords: truss bridge, cold formed, pedestrian, lower deck, SNI 7971:2013, Eurocode 3 


\section{PENDAHULUAN}

Jembatan rangka batang dengan menggunakan material canai dingin merupakan salah satu alternatif untuk menyelesaikan permasalahan jembatan pada daerah terpencil di Indonesia untuk pejalan kaki. Material canai dingin memiliki kelebihan diantaranya kuat tarik yang tinggi, tahan terhadap korosi sehingga relatif lebih awet dan pemeliharaannya mudah, serta pelaksanaannya cepat karena beratnya ringan dan sistem penyambungannya relatif mudah.

Beberapa penelitian tentang jembatan pejalan kaki yang pernah dilakukan oleh beberapa peneliti sebelumnya yaitu, penelitian Nugroho, M. S., Awaludin, A. \& Supriyadi, B. (2017) menunjukkan bahwa perencanaan jembatan pejalan kaki tipe rangka Warren Truss dengan bentang $10 \mathrm{~m}$, serta menggunakan material kayu jati hutan rakyat Blora berdimensi 4x6 cm mampu memikul beban rencana dengan nilai lendutan sebesar 9,9 $\mathrm{mm}$ karena memiliki kekakuan yang paling tinggi.

Pada penelitian sebelumnya yaitu penelitian Refani, A. N., Dibiantara, D., Suluch, M. \& Muqqodam, A. F. (2017) dilakukan analisis struktur mengenai pengaruh bentuk rangka terhadap rasio berat dan lendutan akibat beban pejalan kaki pada jembatan canai dingin bentang pendek sesuai dengan SNI 1725:2016 untuk dasar pembebanan dan SNI 7971:2013 untuk analisis penampang canai dingin. Bentuk rangka jembatan dengan konsep struktur segitiga yang paling optimum berdasarkan rasio berat dan lendutan, dimana lendutan teoritisnya adalah 0,7253 mm dengan berat jembatan 43,38 $\mathrm{kg}$. Bentuk rangka ini juga lebih efisien daripada bentuk rangka yang lain karena lebih stabil.

Oleh karena itu, pada penelitian ini dilakukan suatu analisis untuk mengetahui kapasitas penampang jembatan rangka batang pejalan kaki dengan menggunakan canai dingin berdasarkan SNI 7971:2013 dan Eurocode 3.

\section{TINJAUAN PUSTAKA}

\subsection{Lebar Standar Jembatan Pejalan Kaki}

Menurut SE Menteri Pekerjaan Umum No. 02/SE/M/2010, pengguna jembatan dan tingkat lalu lintas harus diidentifikasi secara jelas karena akan menentukan lebar lantai jembatan yang diperlukan dan beban hidup pada jembatan. Dua lebar standar yang dianjurkan yaitu:

a. $1 \mathrm{~m}-1,4 \mathrm{~m}$ untuk pejalan kaki dua arah (jembatan pejalan kaki kelas II)

b. 1,4 $\mathrm{m}-1,8 \mathrm{~m}$ untuk tiga pejalan kaki yang beriringan (jembatan pejalan kaki kelas I)

Pada penelitian ini, jembatan rangka batang pejalan kaki memiliki lebar lantai jembatan 1,8 $\mathrm{m}$ dengan bentang jembatan $12 \mathrm{~m}$ sehingga dapat diklasifikasikan sebagai jembatan pejalan kaki kelas I.

\subsection{Pembebanan Jembatan Rangka Batang Pejalan Kaki}

Standar mengenai pembebanan dalam perancangan jembatan rangka batang pejalan kaki pada penelitian ini akan mengacu SNI 1725:2016. Beban-beban yang akan diperhitungkan meliputi berat mati sendiri (MS), beban pejalan kaki (TP), beban angin pada struktur (EWs), dan beban gempa (EQ).

\subsection{Persyaratan Desain Eurocode 3}

EN 1993:2006 merupakan standar yang mengatur persyaratan minimum untuk merancang elemen struktur dari material canai dingin (cold formed) seperti profil kanal dan profil lainnya 
yang banyak digunakan sebagai material konstruksi. Persyaratan perancangan yang diatur dalam EN 1993:2006 adalah sebagai berikut:

\subsubsection{Kapasitas Batang Tarik}

Kapasitas batang tarik untuk profil canai dingin dengan tegangan seragam, diatur dalam EN 1993-1-3:2006 dengan nilai $\gamma_{M 0}$ (faktor parsial tahanan penampang akibat leleh) adalah 1,00. Persamaan kapasitas batang tarik dapat dilihat pada Persamaan 1 berikut:

$$
N_{t, R d}=\frac{f_{y a} A_{g}}{\gamma_{M 0}}
$$

dengan:

$N_{t, R d}=$ kapasitas batang tarik [kN],

$f_{y a}=$ kuat leleh rata-rata $[\mathrm{MPa}]$,

$A_{g} \quad=$ area bruto dari penampang melintang $\left[\mathrm{mm}^{2}\right]$.

\subsubsection{Kapasitas Batang Tekan}

Kapasitas batang tarik untuk profil canai dingin dengan tegangan seragam, diatur dalam EN 1993-1-3:2006 dengan ketentuan sebagai berikut:

a. Jika luas area efektif $\left(A_{e f f}\right)$ besarnya kurang dari luas area kotor $\left(A_{g}\right)$, dikarenakan area efektif akan mengalami pengurangan yang diakibatkan tekuk lokal dan/atau tekuk distorsi. Maka, besarnya kapasitas batang tekan harus memenuhi Persamaan $\mathbf{2}$ berikut:

$$
N_{c, R d}=\frac{A_{e f f} f_{y b}}{\gamma_{M 0}}
$$

dengan:

$N_{c, R d} \quad=$ kapasitas batang tekan [kN],

$A_{\text {eff }} \quad=$ penampang efektif $\left[\mathrm{mm}^{2}\right]$,

$f_{y b} \quad=$ kuat leleh baja $[\mathrm{MPa}]$.

b. Jika luas area efektif $\left(\left(A_{e f f}\right)\right.$ sama dengan luas area kotor $\left(A_{g}\right)$,), dikarenakan area efektif tidak mengalami pengurangan yang diakibatkan tekuk lokal dan/atau tekuk distorsi. Maka, besarnya kapasitas batang tekan harus memenuhi Persamaan 3 berikut:

$$
N_{c, R d}=\frac{A_{g}\left(f_{y b}+\left(f_{y a}-f_{y b}\right) 4\left(1-\frac{\lambda_{e}}{\lambda_{e 0}}\right)\right)}{\gamma_{M 0}}
$$

dengan:

$N_{c, R d} \quad=$ kapasitas batang tekan [kN],

$A_{g} \quad=$ area bruto dari penampang melintang $\left[\mathrm{mm}^{2}\right]$,

$f_{y a} \quad=$ kuat leleh rata-rata $[\mathrm{MPa}]$,

$f_{y b} \quad=$ kuat leleh baja [MPa],

$\lambda_{e}, \lambda_{e 0}=$ faktor reduksi penampang,

$=0,673$ untuk elemen tanpa pengaku,

$=0,65$ untuk elemen dengan pengaku.

\subsubsection{Desain Sambungan Baut}

Ketentuan mengenai desain sambungan untuk joint pada struktur jembatan rangka batang canai dingin pejalan kaki terdapat pada Tabel 8.4 EN 1993-1-3:2006 tentang Design 
resistances for bolts, maka perancangan sambungan pada penelitian ini mengacu pada Persamaan 4, Persamaan 5, Persamaan 6, dan Persamaan 7 berikut:

a. Bearing Resistance $\left(F_{b, R d}\right)$

$$
F_{b, R d}=2,5 \frac{\alpha_{b} k_{t} f_{u} d t}{\gamma_{M 2}}
$$

dengan:

$\alpha_{b} \quad=$ nilai terkecil dari 1,0 atau $e_{1} / 3 d ;$

$e_{1} \quad=$ jarak tepi dari sambungan ke baut arah horisontal penampang [mm];

$k_{t} \quad=(0,8 t+1,5) / 2,5$ untuk $0,75 \mathrm{~mm} \leq t \leq 1,25 \mathrm{~mm}$;

$=1,0$ untuk $t>1,25 \mathrm{~mm}$;

$f_{u} \quad=$ kuat tekan maksimum baut [MPa];

$d \quad=$ diameter nominal sambungan $[\mathrm{mm}] ;$

$t \quad=$ tebal bagian tertipis dari sambungan $[\mathrm{mm}] ;$

$\gamma_{M 2}=$ faktor parsial untuk menghitung resistensi desain sambungan mekanis.

b. Net-Section Resistance $\left(F_{n, R d}\right)$

$$
F_{n, R d}=\left(1+3 r\left(\frac{d_{0}}{u}-0,3\right)\right) \frac{A_{n e t} f_{u}}{\gamma_{M 2}} \leq \frac{A_{n e t} f_{u}}{\gamma_{M 2}}
$$

dengan:

$r \quad=$ rasio antara jumlah baut pada penampang dengan total jumlah baut pada sambungan,

$d_{0} \quad=$ diameter nominal lubang $[\mathrm{mm}]$,

$A_{\text {net }} \quad=$ luas netto dari penampang sambungan $\left[\mathrm{mm}^{2}\right]$,

$f_{u} \quad=$ kuat tekan maksimum baut [MPa],

$\gamma_{M 2}=$ faktor parsial untuk menghitung resistensi desain sambungan mekanis,

$u \quad=2 e_{2} \leq p_{2}$,

$p_{2} \quad=$ jarak antar baut arah vertikal $[\mathrm{mm}]$,

$e_{2} \quad=$ jarak tepi dari sambungan ke baut arah vertikal penampang [mm].

C. Shear Resistance $\left(F_{v, R d}\right)$

$$
F_{v, R d}=\frac{0,6 f_{u b} A_{S}}{\gamma_{M 2}}
$$

dengan:

$f_{u b} \quad=$ kuat tarik ultimit dari material sambungan [MPa],

$A_{s} \quad=$ area tegangan tarik sambungan $\left[\mathrm{mm}^{2}\right]$,

$\gamma_{M 2}=$ faktor parsial untuk menghitung resistensi desain sambungan mekanis.

d. Tension Resistance $\left(F_{t, R d}\right)$

$$
F_{t, R d}=\frac{0,9 f_{u b} A_{s}}{\gamma_{M 2}}
$$

dengan:

$f_{u b} \quad=$ kuat tarik ultimit dari material sambungan [MPa],

$A_{S} \quad=$ area tegangan tarik sambungan $\left[\mathrm{mm}^{2}\right]$,

$\gamma_{M 2}=$ faktor parsial untuk menghitung resistensi desain sambungan mekanis. 


\subsection{Persyaratan Desain SNI 7971:2013}

Dalam penelitian ini komponen penampang jembatan rangka canai dingin juga dirancang dengan menggunakan Standar Nasional Indonesia (SNI), hal ini bertujuan untuk dapat mengetahui jika ada tahapan perancangan yang berbeda dengan Eurocode 3. Persyaratan perancangan yang diatur dalam SNI 7971:2013 adalah sebagai berikut:

\subsubsection{Kapasitas Batang Tarik}

Ketentuan mengenai kapasitas batang tarik untuk profil canai dingin terdapat pada SNI 7971:2013 dapat dilihat pada Persamaan 8 berikut:

$$
N^{*} \leq \phi_{t} N_{t}
$$

dengan:

$\phi_{t} \quad=$ faktor reduksi kapasitas untuk batang tarik,

$N_{t} \quad=$ kapasitas penampang nominal batang tarik yang ditentukan sesuai dengan Pasal $3.2 .2[\mathrm{kN}]$.

\subsubsection{Kapasitas Batang Tekan}

Ketentuan mengenai kapasitas batang tekan untuk profil canai dingin terdapat pada SNI 7971:2013 dapat dilihat pada Persamaan 9 dan Persamaan 10 berikut:

$$
\begin{aligned}
& N^{*} \leq \phi_{c} N_{S} \\
& N^{*} \leq \phi_{c} N_{c}
\end{aligned}
$$

dengan:

$\phi_{c} \quad=$ faktor reduksi kapasitas untuk batang tekan,

$N_{S} \quad=$ kapasitas penampang nominal dari batang tekan [kN],

$N_{c} \quad=$ kapasitas komponen struktur nominal dari batang tekan [kN].

\subsubsection{Desain Sambungan Baut}

Ketentuan mengenai perancangan sambungan baut untuk joint pada struktur jembatan rangka batang canai dingin pejalan kaki terdapat pada SNI 7971:2013 seperti terlihat pada Persamaan 11, Persamaan 12, Persamaan 13, dan Persamaan 14 berikut:

a. Kapasitas Tumpu

$$
\phi V_{b}=\phi \alpha C d_{f} t f_{u}
$$

dengan:

$\phi=$ faktor reduksi,

$\alpha=$ faktor modifikasi untuk tipe sambungan tumpu,

$C=$ faktor tumpu,

$d_{f}=$ diameter baut nominal [mm],

$t=$ tebal logam dasar [mm],

$f_{u}=$ kekuatan tarik lembaran [MPa].

b. Baut dalam Geser

$$
\phi V_{f v}=\phi 0,62 f_{u f}\left(n_{n} A_{c}+n_{x} A_{0}\right)
$$


dengan:

$f_{u f}=$ kekuatan tarik minimum satu baut [MPa],

$n_{n}=$ jumlah bidang geser dengan ulir pada bidang geser,

$A_{c}=$ luas diameter minor satu baut $\left[\mathrm{mm}^{2}\right]$,

$n_{x}=$ jumlah bidang geser tanpa ulir pada bidang geser,

$A_{0}=$ luas penampang baut tanpa ulir $\left[\mathrm{mm}^{2}\right]$.

c. Baut dalam Tarik

$$
\phi N_{f t}=\phi A_{s} f_{u f}
$$

dengan:

$A_{s}=$ luas tegangan tarik satu baut $\left[\mathrm{mm}^{2}\right]$,

$f_{u f}=$ kekuatan tarik minimum satu baut $[\mathrm{MPa}]$.

d. Baut dalam Kombinasi Geser dan Tarik

$$
\left[\frac{V_{f v}^{*}}{\phi V_{f v}}\right]^{2}+\left[\frac{N_{f t}^{*}}{\phi N_{f t}}\right]^{2} \leq 1,0
$$

dengan:

$V_{f v}^{*} \quad=$ gaya geser desain $[\mathrm{kN}]$,

$V_{f v} \quad=$ kapasitas geser nominal baut $[\mathrm{kN}]$,

$N_{f t}^{*} \quad=$ gaya tarik desain [kN],

$N_{f t} \quad=$ kapasitas tarik nominal baut [kN].

\section{METODE PENELITIAN}

Penelitian ini diawali dengan studi pustaka mengenai penelitian-penelitian bertujuan untuk mengetahui subjek yang akan diteliti, serta metode penelitian yang akan dilaksanakan. Tahap kedua adalah tahap pengumpulan data yang terdiri dari data mutu material dan data dimensi dimensi profil canai dingin seluruh elemen-elemen yang terdapat pada jembatan rangka batang pejalan kaki, serta dimensi dari struktur jembatan itu sendiri. Tahap selanjutnya yaitu tahap pemodelan jembatan rangka batang canai dingin pejalan kaki tipe lower deck dengan menggunakan program SAP2000. Adapun data geometri jembatan yang akan dianalisis seperti terlihat pada Tabel 1, sedangkan model jembatan ditunjukkan pada Gambar 1. Penelitian ini diakhiri dengan mengidentifikasi kekuatan strukturnya menggunakan 2 standar yang berbeda yaitu Eurocode 3 dan SNI 7971:2013. Hasil analisis kekuatan struktur dengan menggunakan kedua standar tersebut, akan dibandingkan dan ditarik kesimpulan akhir dari penelitian ini.

Tabel 1. Data Geometri Jembatan

\begin{tabular}{lcc}
\hline \multicolumn{1}{c}{ Nama Komponen } & Mutu & Dimensi \\
\hline Panjang jembatan $(\boldsymbol{L})$ & - & $12 \mathrm{~m}$ \\
\hline Lebar jembatan $(\boldsymbol{b})$ & - & $1,8 \mathrm{~m}$ \\
\hline Sistem panel lantai & $\mathrm{SS} 400$ & $2 \mathrm{~m} \times 1,8 \mathrm{~m}$ \\
\hline Rangka vertikal \& horisontal & $\mathrm{G} 550$ & $2 \mathrm{U} 95 \times 64 \times 2$ \\
\hline Rangka diagonal & $\mathrm{G} 550$ & $2 \mathrm{U} 95 \times 70 \times 2$ \\
\hline Gelagar melintang & $\mathrm{G} 550$ & $2 \mathrm{U} 95 \times 64 \times 2$ \\
\hline Gelagar memanjang & G550 & $2 \mathrm{U} 95 \times 64 \times 2$ \\
\hline Baut & Grade 4.6 & $\varnothing 8 ; \varnothing 10$ \\
\hline
\end{tabular}

Reka Racana: Jurnal Teknik Sipil - 17 


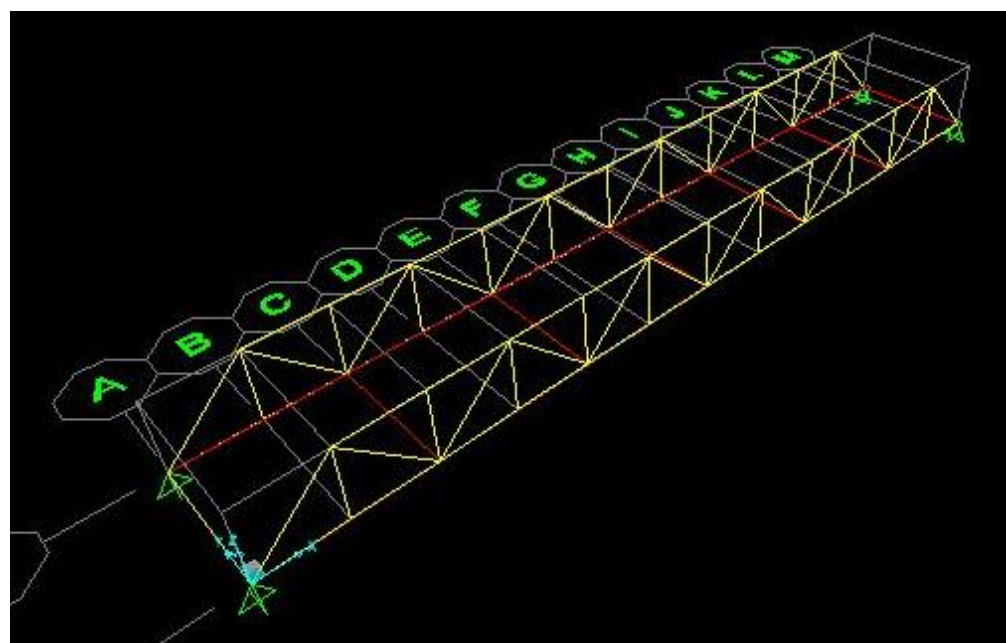

Gambar 1. Pemodelan struktur jembatan rangka batang canai dingin lower deck

\section{ANALISIS DAN PEMBAHASAN}

Pada penelitian ini dilakukan analisis terhadap aspek-aspek struktural jembatan diantaranya analisis lendutan, analisis kapasitas batang tarik dan tekan, serta analisis kebutuhan sambungan setiap jembatan berdasarkan Eurocode 3 dan SNI 7971:2013.

\subsection{Analisis Lendutan}

Nilai lendutan hasil analisis struktur jembatan rangka batang canai dingin pejalan kaki tipe lower deck menggunakan ketentuan yang berdasarkan Eurocode 3 dan SNI 7971:2013 disajikan pada Tabel $\mathbf{2}$.

Tabel 2. Analisis Lendutan Desain

\begin{tabular}{cccc} 
Jenis Dek & $\begin{array}{c}\text { Lendutan Desain } \\
{[\mathrm{m}]}\end{array}$ & \multicolumn{2}{c}{$\begin{array}{c}\text { Lendutan Izin } \\
{[\mathrm{m}]}\end{array}$} \\
\cline { 2 - 4 } & Eurocode 3 & SNI 7971:2013 \\
Lower & 0,0011 & 0,02 & 0,015 \\
\hline
\end{tabular}

Dari hasil analisis diperoleh bahwa struktur jembatan rangka batang canai dingin pejalan kaki tipe lower deck memiliki nilai lendutan sebesar 0,0011 m memenuhi syarat lendutan izin baik Eurocode 3 maupun SNI 7971:2013.

\subsection{Analisis Kapasitas Batang Tarik dan Batang Tekan}

Kapasitas penampang baik batang tarik maupun batang tekan hasil analisis struktur jembatan rangka batang canai dingin pejalan kaki tipe lower deck menggunakan ketentuan berdasarkan Eurocode 3 dan SNI 7971:2013 seperti terlihat pada Tabel 3.

Tabel 3. Analisis Kapasitas Batang Tarik dan Batang Tekan

\begin{tabular}{ccccc}
\hline \multirow{2}{*}{ Jenis Dek } & Elemen Jembatan & \multirow{2}{*}{$\begin{array}{c}\text { Beban } \\
{[\mathbf{k N}]}\end{array}$} & \multicolumn{2}{c}{ Kapasitas Penampang } \\
\cline { 3 - 5 } & & & \multicolumn{2}{c}{ [kN] } \\
\hline \multirow{2}{*}{ Lower } & Batang Tarik & 149,10 & 349,80 & 247,40 \\
\cline { 2 - 5 } & Batang Tekan & $-157,06$ & 349,80 & 288,14 \\
\hline
\end{tabular}

Pada Tabel $\mathbf{3}$ di atas terlihat nilai kapasitas penampang baik batang tarik maupun batang tekan berdasarkan Eurocode 3 memiliki kesamaan hasil. Hal ini dikarenakan, pada asumsi kuat 
leleh rata-rata dan kuat leleh dasar bernilai sama sehingga persamaan kapasitas batang tarik akan sama dengan persamaan kapasitas batang tekan.

Dari data di atas dapat diperoleh rasio antara beban dan kapasitas penampang dengan menggunakan Persamaan 15 berikut:

$$
\frac{P_{u}}{\phi P_{n}} \leq 1,00
$$

dengan:

$P_{n}=$ kapasitas aktual penampang $[\mathrm{kN}]$,

$P_{u}=$ kapasitas desain penampang $[\mathrm{kN}]$.

Adapun rasio antara beban dan kapasitas penampang disajikan pada Tabel $\mathbf{4}$ dan Gambar 2.

Tabel 4. Rasio antara Beban terhadap Kapasitas Penampang

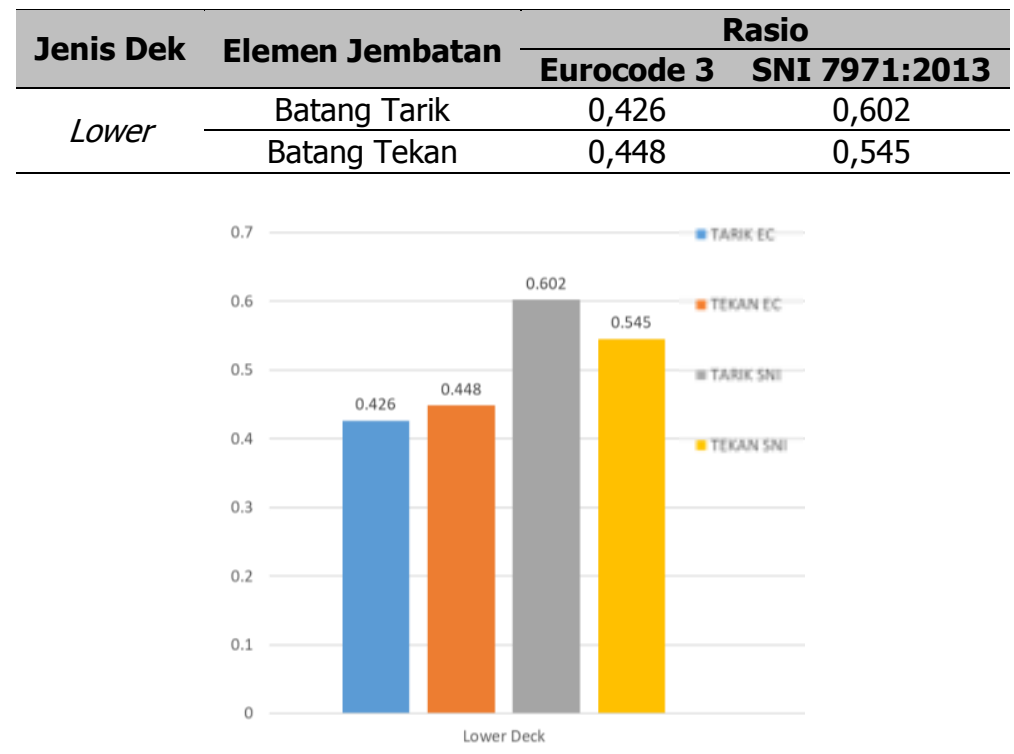

Gambar 2. Grafik rasio beban terhadap kapasitas penampang

\subsection{Analisis Kebutuhan Sambungan}

Jumlah kebutuhan sambungan pada jembatan rangka batang canai dingin pejalan kaki tipe lower deck menggunakan ketentuan berdasarkan Eurocode 3 lebih banyak dibandingkan SNI 7971:2013 seperti terlihat pada Gambar 3 dan Gambar 4. Hal ini dimungkinkan, karena kapasitas penampang batang baik tarik maupun tekan berdasarkan Eurocode 3 lebih besar dibandingkan SNI 7971:2013. 


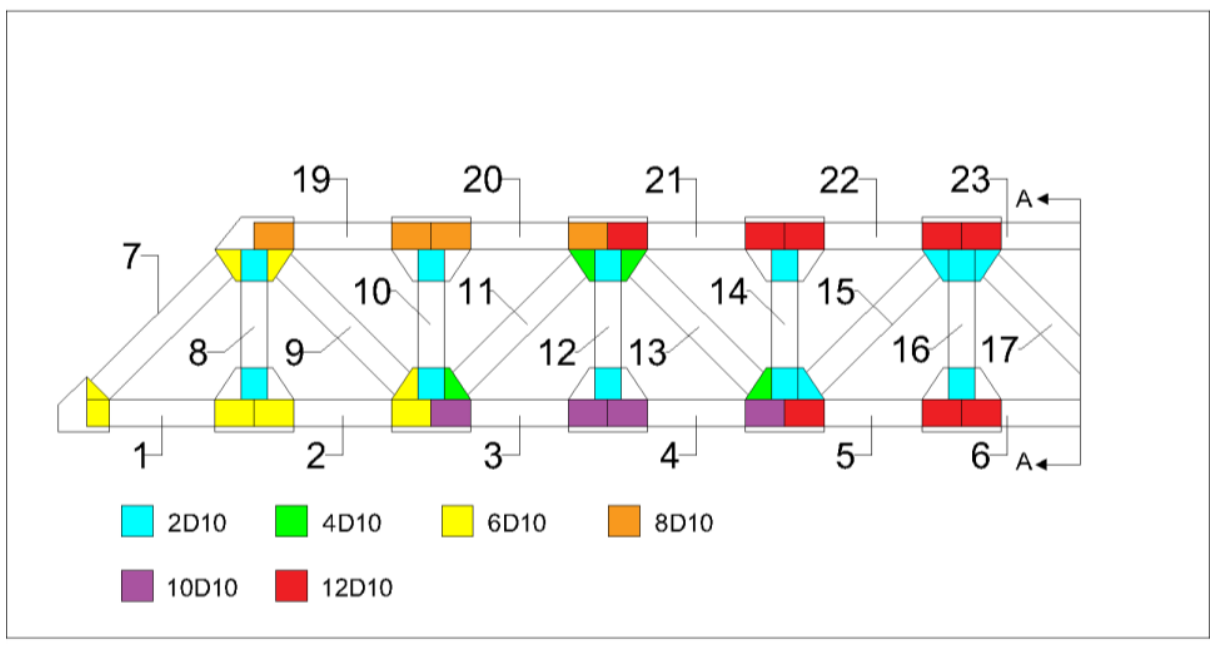

Gambar 3. Kebutuhan sambungan jembatan Lower Deck Eurocode 3

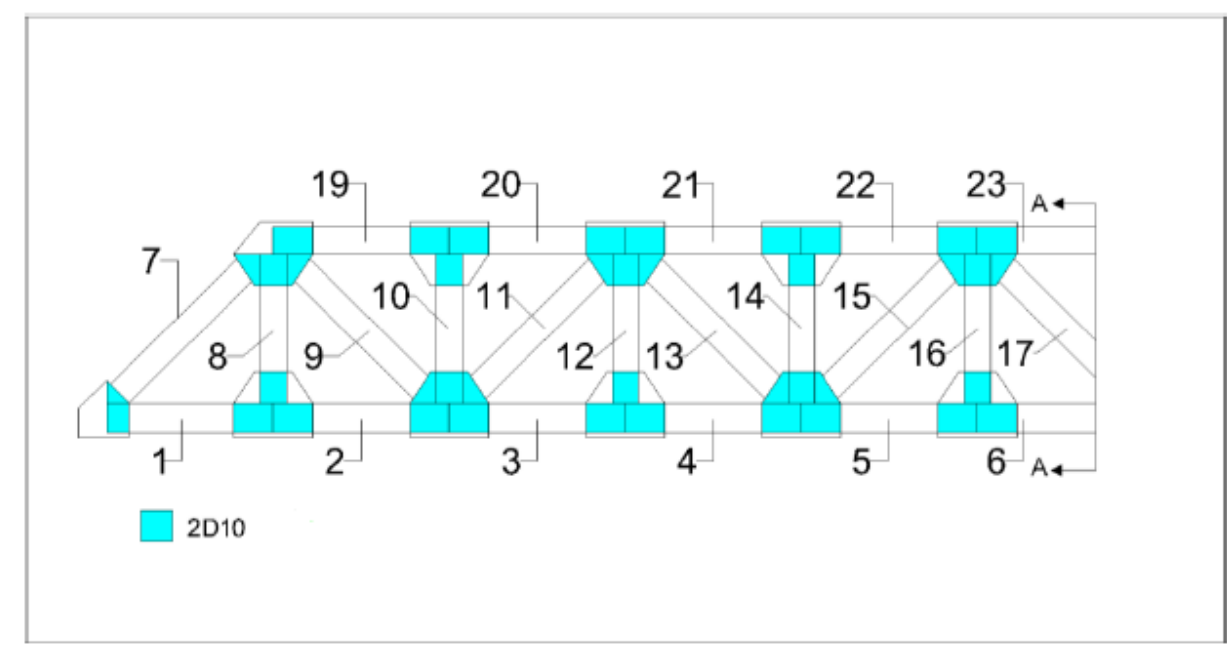

Gambar 4. Kebutuhan sambungan jembatan Lower Deck SNI 7971:2013

\section{KESIMPULAN DAN SARAN}

\subsection{Kesimpulan}

Dari hasil perhitungan dan analisis pada penelitian yang telah dilakukan, maka dapat ditarik kesimpulan sebagai berikut:

1. Jembatan rangka batang canai dingin pejalan kaki tipe lower deck memiliki kekuatan struktur yang baik untuk menahan beban-beban yang direncanakan. Elemen-elemen struktur jembatan rangka batang canai dingin pejalan kaki tipe lower deck memiliki kapasitas penampang dan nilai lendutan yang memenuhi ketentuan berdasarkan Eurocode 3 maupun SNI 7971:2013.

2. Berdasarkan hasil analisis struktur elemen jembatan rangka batang canai dingin pejalan kaki tipe lower deck memiliki rasio beban terhadap kapasitas batang tarik sebesar 0,426 dan rasio beban terhadap kapasitas batang tekan sebesar 0,448 untuk Eurocode 3; sedangkan rasio beban terhadap kapasitas batang tarik sebesar 0,602 dan untuk rasio beban terhadap kapasitas batang tekan sebesar 0,545 untuk SNI 7971:2013. 


\subsection{Saran}

Adapun saran untuk penelitian selanjutnya sebagai berikut:

1. Dilakukan penelitian pada jembatan rangka batang canai dingin pejalan kaki tipe upper deck.

2. Dilakukan analisis tambahan menggunakan kombinasi pembebanan berdasarkan Eurocode 3 untuk respon struktur jembatan secara keseluruhan.

\section{DAFTAR RUJUKAN}

Badan Standardisasi Nasional. (2013). SNI 7971:2013 tentang Spesifikasi Desain untuk Konstruksi Baja Canai Dingin. Jakarta: Badan Standardisasi Nasional.

Badan Standardisasi Nasional. (2016). SNI 1725:2016 tentang Pembebanan untuk Jembatan. Jakarta: Badan Standardisasi Nasional.

BS EN 1993:2006. (2006). Cold Formed Structures. Strength classes and determination of characteristic values. British Standards Institution.

Nugroho, M. S., Awaludin, A. \& Supriyadi, B. (2017). Perencanaan Jembatan Pejalan Kaki Menggunakan Kayu Jati Hutan Rakyat Sebagai Material Konstruksi. INERSIA, XIII(2), 141-153.

Refani, A. N., Dibiantara, D., Suluch, M. \& Muqqodam, A. F. (2017). Studi Alternatif Bentuk Rangka Jembatan Canai Dingin Untuk Pejalan Kaki Bentang Kecil Terhadap Rasio Berat dan Lendutan. Jurnal Aplikasi Teknik Sipil, 15(1), 25-30.

Surat Edaran Menteri Pekerjaan Umum No. 02/SE/M/2010 . (2010). Pemberlakuan Pedoman Perencanaan dan Pelaksanaan Konstruksi Jembatan Gantung Untuk Pejalan Kaki. Jakarta: Kementrian Pekerjaan Umum. 